\title{
In vivo antigen expression regulates CD4 T cell differentiation and vaccine efficacy against mycobacterium tuberculosis infection
}

Clemmensen, Helena Strand; Dube, Jean Yves; Mclntosh, Fiona; Rosenkrands, Ida; Jungersen, Gregers; Aagaard, Claus; Andersen, Peter; Behr, Marcel A.; Mortensen, Rasmus

\section{Published in:}

mBio (Online)

Link to article, DOI:

10.1128/mBio.00226-21

Publication date:

2021

Document Version

Publisher's PDF, also known as Version of record

Link back to DTU Orbit

Citation (APA):

Clemmensen, H. S., Dube, J. Y., Mclntosh, F., Rosenkrands, I., Jungersen, G., Aagaard, C., Andersen, P., Behr, M. A., \& Mortensen, R. (2021). In vivo antigen expression regulates CD4 T cell differentiation and vaccine efficacy against mycobacterium tuberculosis infection. mBio (Online), 12(2), [e00226-21]. https://doi.org/10.1128/mBio.00226-21

\section{General rights}

Copyright and moral rights for the publications made accessible in the public portal are retained by the authors and/or other copyright owners and it is a condition of accessing publications that users recognise and abide by the legal requirements associated with these rights.

- Users may download and print one copy of any publication from the public portal for the purpose of private study or research.

- You may not further distribute the material or use it for any profit-making activity or commercial gain

- You may freely distribute the URL identifying the publication in the public portal 


\title{
In Vivo Antigen Expression Regulates CD4 T Cell Differentiation and Vaccine Efficacy against Mycobacterium tuberculosis Infection
}

\author{
(D) Helena Strand Clemmensen, ${ }^{a, b}$ Jean-Yves Dube, ${ }^{d, e, f f}$ Fiona McIntosh, ${ }^{e, f}$ Ida Rosenkrands, ${ }^{a}$ Gregers Jungersen,

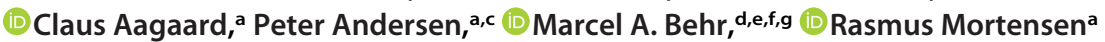 \\ aDepartment of Infectious Disease Immunology, Statens Serum Institut, Copenhagen, Denmark \\ bDepartment of Health Technology, Technical University of Denmark, Kongens Lyngby, Denmark \\ cDepartment of Immunology and Microbiology, University of Copenhagen, Copenhagen, Denmark \\ dDepartment of Microbiology and Immunology, McGill University, Montréal, Canada \\ elnfectious Diseases and Immunity in Global Health Program, Research Institute of the McGill University Health Centre, Montréal, Canada \\ fMcGill International TB Centre, Montréal, Canada \\ gDepartment of Medicine, McGill University Health Centre, Montréal, Canada
}

ABSTRACT New vaccines are urgently needed against Mycobacterium tuberculosis (Mtb), which kills more than 1.4 million people each year. CD4 T cell differentiation is a key determinant of protective immunity against Mtb, but it is not fully understood how host-pathogen interactions shape individual antigen-specific $T$ cell populations and their protective capacity. Here, we investigated the immunodominant Mtb antigen, MPT70, which is upregulated in response to gamma interferon (IFN- $\gamma$ ) or nutrient/ oxygen deprivation of in vitro-infected macrophages. Using a murine aerosol infection model, we compared the in vivo expression kinetics of MPT70 to a constitutively expressed antigen, ESAT-6, and analyzed their corresponding CD4 T cell phenotype and vaccine protection. For wild-type Mtb, we found that in vivo expression of MPT70 was delayed compared to ESAT-6. This delayed expression was associated with induction of less differentiated MPT70-specific CD4 T cells but, compared to ESAT-6, also reduced protection after vaccination. In contrast, infection with an MPT70-overexpressing Mtb strain promoted highly differentiated $\mathrm{KLRG} 1{ }^{+} \mathrm{CX} 3 \mathrm{CR} 1{ }^{+} \mathrm{CD} 4 \mathrm{~T}$ cells with limited lung-homing capacity. Importantly, this differentiated phenotype could be prevented by vaccination, and against the overexpressing strain, vaccination with MPT70 conferred protection similar to vaccination with ESAT-6. Together, our data indicate that high in vivo antigen expression drives $\mathrm{T}$ cells toward terminal differentiation and that targeted vaccination with adjuvanted protein can counteract this phenomenon by maintaining $T$ cells in a protective less differentiated state. These observations shed new light on host-pathogen interactions and provide guidance on how future Mtb vaccines can be designed to tip the immune balance in favor of the host.

IMPORTANCE Tuberculosis, caused by Mtb, constitutes a global health crisis of massive proportions and the impact of the current coronavirus disease 2019 (COVID-19) pandemic is expected to cause a rise in tuberculosis-related deaths. Improved vaccines are therefore needed more than ever, but a lack of knowledge on protective immunity hampers their development. The present study shows that constitutively expressed antigens with high availability drive highly differentiated CD4 T cells with diminished protective capacity, which could be a survival strategy by Mtb to evade $\mathrm{T}$ cell immunity against key antigens. We demonstrate that immunization with such antigens can counteract this phenomenon by maintaining antigen-specific $T$ cells in a state of low differentiation. Future vaccine strategies should therefore explore combinations of multiple highly expressed antigens and we suggest that $\mathrm{T}$ cell
Citation Clemmensen HS, Dube J-Y, Mclntosh F, Rosenkrands I, Jungersen G, Aagaard C, Andersen P, Behr MA, Mortensen R. 2021. In vivo antigen expression regulates $C D 4 T$ cell differentiation and vaccine efficacy against Mycobacterium tuberculosis infection. mBio 12 e00226-21. https://doi.org/10.1128/mBio .00226-21.

Editor Alan Sher, National Institute of Allergy and Infectious Diseases

Copyright $\odot 2021$ Clemmensen et al. This is an open-access article distributed under the terms of the Creative Commons Attribution 4.0 International license.

Address correspondence to Rasmus Mortensen, rjm@ssi.dk.

Received 29 January 2021

Accepted 10 March 2021

Published 20 April 2021 
differentiation could be used as a readily measurable parameter to identify these in both preclinical and clinical studies.

KEYWORDS vaccination, MPT70, ESAT-6, immunization, in vivo expression, Mycobacterium tuberculosis, T cell differentiation

ycobacterium tuberculosis (Mtb) has successfully survived in the human host for thousands of years and still causes 1.4 million deaths from tuberculosis (TB) disease annually (1). Formation of the granuloma is associated with the containment of infection, as the environment within the granuloma suppresses Mtb growth in multiple ways, including oxygen and nutrient deprivation, exposure to acidic $\mathrm{pH}$, and production of endogenous nitric oxide. In response to this, Mtb adapts by shifting between metabolic states often characterized by alterations in gene expression and thus changes in protein secretion and antigenic repertoire (2-5).

As part of evolutionary adaptation, virulent strains across the mycobacterial tuberculosis complex (MTBC) vary in their expression of certain antigens, like the major secreted immunogenic protein 70 (MPT70) (6). Mtb produces very small amounts of MPT70 in in vitro cultures (7), but multiple studies have demonstrated that gamma interferon (IFN- $\gamma$ ) activation $(5,6)$ or starvation (8) induces MPT70 expression upon in vitro infection. Although MPT70 is a well-known immunodominant antigen during Mtb infection in both mice and humans (9-13), nothing is known about how MPT70's in vivo antigen expression profile relates to the $\mathrm{T}$ cell phenotype it induces and its protective capacity as a vaccine antigen (13-16).

CD4 T cells are essential for protective immunity against Mtb (17-20), and there is mounting evidence that CD4 T cells develop into terminally differentiated IFN- $\gamma$-producing effector $T$ cells upon continuous antigen stimulation (21-23). The development of effector CD4 T cells is linked to sustained expression of markers and chemokine receptors associated with terminal Th1 differentiation and poor lung homing $(24,25)$. Less differentiated $\mathrm{CXCR}^{+}{ }^{+}$-bet ${ }^{\text {dim }}$ CD4 $\mathrm{T}$ cells are able to enter the lung parenchyma and inhibit Mtb growth $(25,26)$, while terminally differentiated CD4 T cells coexpressing CX3CR1 and KLRG1 accumulate in the lung vasculature and provide no pulmonary control of Mtb infection $(27,28)$. Individual differences in antigen expression are suggested to shape $T$ cell phenotype (22) and may therefore be a key determinant of vaccine protection.

The goal of this study was to investigate the impact of in vivo antigen expression on antigen recognition kinetics and adaptive immunity during Mtb infection, with MPT70 as a unique tool. Using the well-described 6-kDa early secretory antigenic target (ESAT-6) as a prototypic immunodominant model antigen $(22,29-31)$, we show that MPT70 displays delayed in vivo antigen expression as well as delayed immune recognition. This is associated with the induction of less differentiated CD4 T cells but also lower protection in mice vaccinated with MPT70. On the basis of these observations, we hypothesize that high constitutive antigen expression is associated with increased $\mathrm{T}$ cell differentiation but also improved vaccine capacity. In support of this, we demonstrate that artificial overexpression of MPT70 leads to accelerated CD4 T cell differentiation and diminished lung-homing capacity. However, vaccination with MPT70 counteracts this by stabilizing a low degree of T cell differentiation and increases protection substantially in the MPT70overexpressing strain compared to wild-type (WT) Mtb. Our study therefore reveals that antigen expression kinetics regulates CD4 T cell differentiation during infection and establishes a link between in vivo antigen expression, $T$ cell differentiation, and vaccine protective capacity. This has implications for rational vaccine design, and future efforts in TB antigen discovery might use antigen-specific T cell differentiation as a readily measurable proxy for high in vivo antigen expression and increased vaccine potential.

\section{RESULTS}

Delayed in vivo antigen transcription results in late immune recognition of MPT70. Previous studies indicate that MPT70 expression by Mtb is very low during in vitro cultivation $(7,11)$ but that expression is induced upon IFN- $\gamma$ activation $(5,6)$ or 


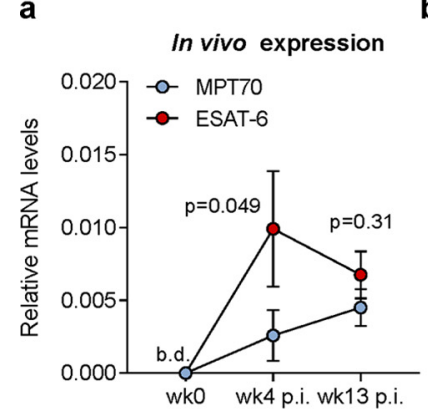

b

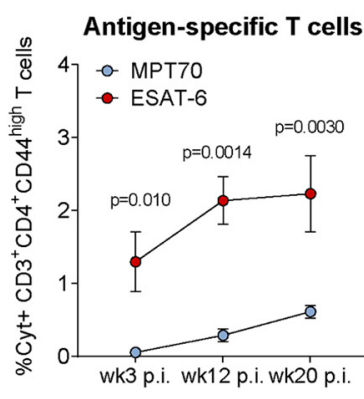

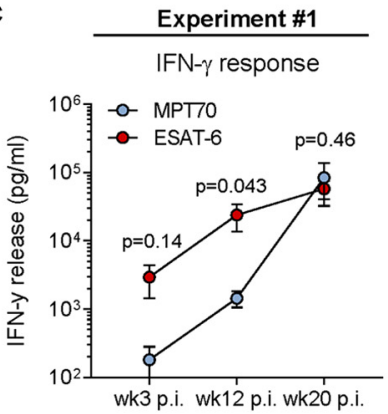

Experiment \#2

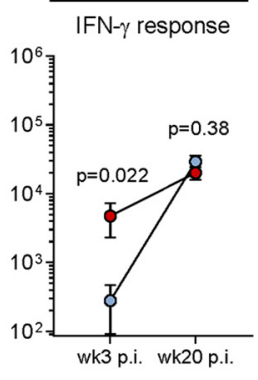

FIG 1 In vivo antigen expression and immune recognition of MPT70 are delayed during M. tuberculosis (Mtb) Erdman infection. CB6F1 mice were infected by the aerosol route with Mtb Erdman. (a) MPT70 and ESAT-6 in vivo gene expression were assessed preinfection (week 0 [wk0]) and 4 and 13 weeks postinfection (p.i.) $(n=4)$. The expression preinfection was below detection levels (b.d.). Values shown are means \pm standard errors of the means (SEM) (error bars). A two-tailed, paired $t$ test was used to assess statistical differences. (b, left) At weeks 3,12 , and 20 after Mtb infection, lungs were harvested for immunological analyses. The frequency of cytokine-producing CD3 ${ }^{+} \mathrm{CD}^{+} \mathrm{T}$ cells specific for MPT70 and ESAT-6 for the same time points as shown in panel c, experiment 1 (medium cytokine production subtracted) analyzed by flow cytometry using the antibodies shown in Table 3 ( $n=4$ ). Values shown are means \pm SEM. One-way analysis of variance (ANOVA) with Tukey's multiple-comparison test was used to assess statistical differences. (b, right) Fold change in cytokine-producing CD4 T cells from baseline. (c) Lung cells from infected mice were restimulated in vitro with media, MPT70, or ESAT-6 for 5 days. Culture supernatant was harvested and measured for IFN- $\gamma$ levels in two individual experiments $(n=4)$. Values were log transformed and shown as means \pm SEM. A two-tailed, paired $t$ test was used to assess statistical differences.

nutrient deprivation (8). On the basis of these studies, we hypothesized that in vivo transcription and immune recognition of MPT70 would be delayed compared to ESAT6 , a constitutively expressed virulence factor $(32,33)$.

To map the kinetics of MPT70 expression in vivo, we infected a group of CB6F1 mice with Mtb Erdman, which we expected to produce small amounts of MPT70 (7). RNA was extracted from the postcaval lobe, and cDNA was quantified by real-time quantitative PCR (qPCR) using dually labeled probes and normalized to $16 \mathrm{~S}$ rRNA. Expression levels of MPT70 and ESAT- 6 mRNA were analyzed prior to infection (week 0 ), at an early time point (week 4), and at a late time point (week 13). As expected, expression levels were below detection level prior to infection (Fig. 1a). At week 4, MPT70 expression was low and significantly lower than ESAT-6, but as the infection progressed to week 13, MPT70 expression increased and approached levels of ESAT-6, indicating a delayed expression profile (Fig. 1a).

We next investigated the kinetics of the immune recognition to the two antigens during the course of infection. Mice were infected as previously and antigen-specific immune responses were detected at 3, 12, and 20 weeks postinfection, either by intracellular cytokine staining (ICS) measuring the frequency of antigen-specific CD4 T cells producing interleukin 2 (IL-2), tumor necrosis factor alpha (TNF- $\alpha$ ), or IFN- $\gamma$ (Fig. 1b; see also Fig. $\mathrm{S} 1$ in the supplemental material) or IFN- $\gamma$ release in cultures of stimulated splenocytes (Fig. 1C). Notably, in two independent experiments, we observed that the immune recognition of MPT70 was very low in the early phase of infection but continued to increase as the infection progressed to week 12 and 20 (Fig. $1 \mathrm{~b}$ and c). This was in contrast to ESAT- 6 responses that were greater at week 3 and 12, after which they plateaued.

Together, these data indicate that in vivo expression of MPT70 is delayed compared to ESAT-6 and that this difference in kinetics is associated with lower initial CD4 T cell responses and/or a delayed onset MPT70-specific adaptive immunity.

MPT70-specific CD4 T cells maintain a low degree of differentiation. Continuous stimulation with high levels of antigen is known to drive T cells toward terminal differentiation (21-23), and we therefore explored whether the delayed antigen availability of MPT70 favored the development of less differentiated T cells during infection. In order to address this, we first characterized MPT70- and ESAT-6-specific T cells according to their expression of intracellular cytokines associated with Th1 differentiation (Fig. S1a). We observed no or little induction of IL-17-producing CD4 T cells and the responding CD4 T cells primarily expressed IFN- $\gamma$, TNF- $\alpha$, or IL-2 (Fig. S1b). As previously defined $(22,34)$, a functional differentiation score (FDS) can be applied as a simple 
Functional Differentiation Score

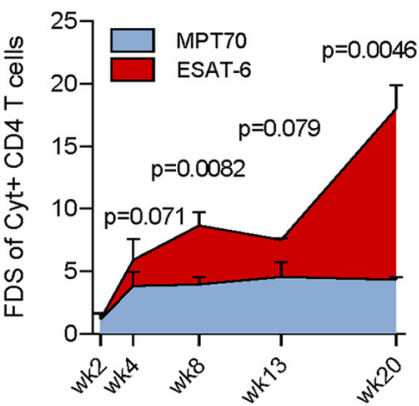

d
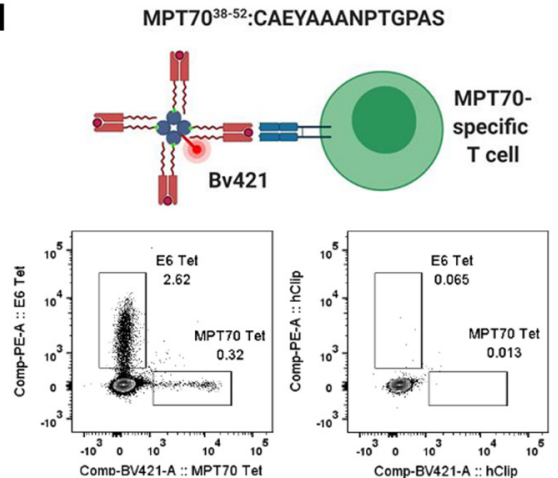

b

KLRG1 expression

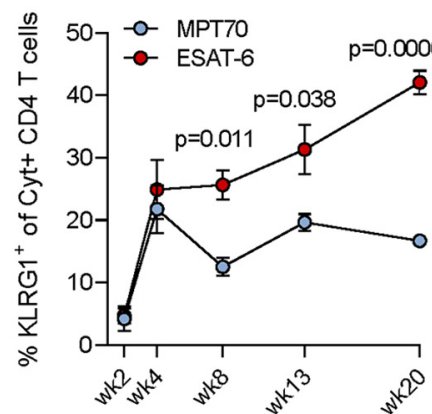

e

Tet $^{+}$CD4 T cells Lung, wk12-16 p.i.

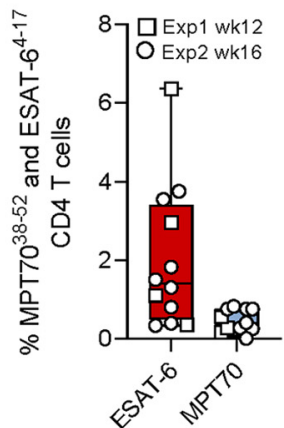

C

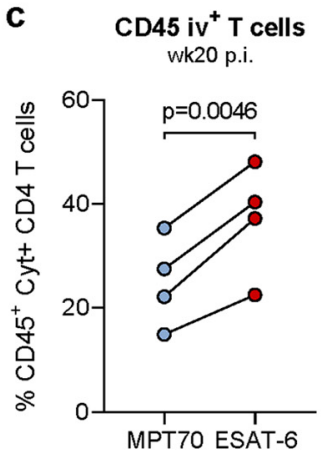

f

Tet $^{+}$CD4 T cells

Lung, wk12-16 p.i.

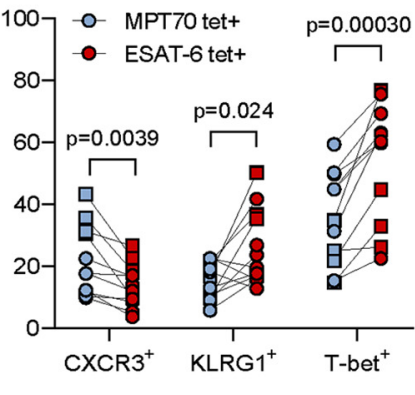

CX3CR1+KLR1+ ESAT-6 CD4 T cells

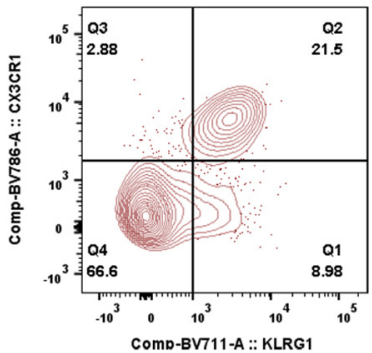

FIG 2 MPT70-specific CD4 T cells maintain a low differentiation state compared to ESAT-6. (a) The functional differentiation score (FDS) of MPT70- and ESAT-6-specific CD4 T cells over the course of Mtb Erdman infection $(n=4)$. The FDS is defined as the ratio of all IFN- $\gamma$-producing CD4 T cell subsets divided by subsets producing other cytokines (IL-2, TNF- $\alpha$ ), but not IFN- $\gamma$ (high FDS $=$ high IFN- $\gamma$ production). Multiple $t$ tests with correction for multiple testing using the Holm-Sidak method were used to assess statistical differences. Values shown are means \pm SEM. Flow cytometry gating is shown as depicted in Fig. S1a in the supplemental material, using the antibodies shown in Table 4. (b) Frequencies of KLRG1-expressing MPT70- and ESAT-6-specific CD4 T cells throughout infection $(n=4)$. Values shown are means \pm SEM. Multiple $t$ tests with correction for multiple testing using the Holm-Sidak method were used to assess statistical differences. (c) Frequency of CD45-labeled MPT70- and ESAT-6-specific CD4 T cells in the lung-associated vasculature (CD45 $\left.{ }^{+}\right)$ 20 weeks postinfection (p.i.) with Mtb $(n=4)$. A two-tailed, paired $t$ test was used. (d, top) Schematic representation of custom-made I-A $\mathrm{A}^{\mathrm{b}}: \mathrm{MPT} 7 \mathrm{O}_{38-52} \mathrm{MHC}^{\mathrm{B}} \mathrm{II}$ tetramer. (d, bottom) Representative concatenated FACS plots showing frequencies of I-A b:MPT70 $_{38-52}$ and I-Ab:ESAT-6 ${ }_{4-17}$ tetramer (Tet)-positive CD4 T cells or corresponding hClip tetramer-positive CD4 T cells in lungs of mice 12 weeks after Mtb infection $(n=4)$. (e) Frequency of I-A $A^{\text {b:MPT70 }}$ B $_{38-52}$ and I-Ab:ESAT- $6^{4}$ ${ }_{17}$ CD4 T cells 12 to 16 weeks after Mtb infection expressing CXCR3, KLRG1, and T-bet. A parametric, two-tailed, paired $t$ test was used to assess statistical differences $(n=12)$. Flow cytometry gating is shown as depicted in Fig. S3 using the antibodies shown in Table 3. (f) Concatenated FACS plot of CX3CR1 ${ }^{+}$ $\mathrm{KLRG}^{+}{ }^{+}$coexpressing ESAT-6 ${ }^{4-17}$ CD4 T cells $(n=4)$.

measure for the T cell differentiation status and is calculated as the ratio of all highly differentiated IFN- $\gamma$ producing $T$ cell subsets divided by less differentiated $T$ cell subsets producing other cytokines (IL-2, TNF- $\alpha$ ). An FDS score of $>1$ is therefore indicative of a response with more highly differentiated $T$ cells than less differentiated $T$ cells. During the first 2 weeks of infection, MPT70- and ESAT-6-specific CD4 T cells displayed similar FDSs in the range of 2. From week 2 to 4 , the FDS of both T cell subsets increased to 3.8 and 5.9, respectively. From week 4 and onwards, the FDS of ESAT-6 T cells continuously increased to reach 18 , while the FDS of MPT70 T cells remained constant around 4, denoting that MPT70 CD4 T cells are not driven toward terminal differentiation to the same extent as ESAT-6 (Fig. 2a). In Mtb-infected mice, CXCR3 ${ }^{+}$KLRG1 $^{-}{ }^{-}$-bet ${ }^{\text {dim }}$ T cells migrate into the lung parenchyma and control the infection $(26,28)$, while intravascular (iv) T cells have a high expression of KLRG1, CX3CR1, and T-bet (24). In accordance with the FDS data, we observed a substantially lower proportion of cytokine-expressing KLRG1+ CD4 T cells after MPT70 stimulation compared to ESAT-6, and this difference was sustained throughout the infection (Fig. 2b). Investigating the ability of these CD4 T cell subsets to enter the infected lung tissue by CD45 iv staining further supported that a smaller fraction of MPT70-specific CD4 T cells were retained in the lung-associated vasculature (CD45 iv $\left.{ }^{+}\right)$ compared to ESAT-6 CD4 T cells (Fig. 2c). 
We next wanted to confirm these observations using a major histocompatibility complex class II (MHC-II) tetramer. In contrast to ICS, tetramers identify antigen-specific $\mathrm{T}$ cells without the risk of affecting the expression of certain markers due to ex vivo stimulation. We therefore epitope mapped the MPT70 protein (29) and developed a murine MHC-II tetramer specific for I-A $\mathrm{A}^{\mathrm{b}}: \mathrm{MPT70}_{38-52}$ (see Materials and Methods, Fig. 2d, and Fig. S2). In the lungs of mice infected with Mtb for 12 to 16 weeks, we found an av-

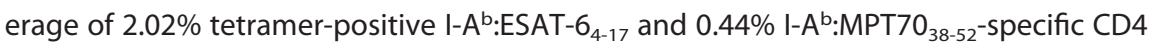
T cells (Fig. 2e). Exploring the expression of CXCR3, KLRG1, CX3CR1, and T-bet showed that $\mathrm{MPT70}_{38-52}$-specific CD4 T cells expressed significantly higher levels of CXCR3 $(P=$ $0.0039)$ and significantly lower levels of KLRG1 $(P=0.024)$ and T-bet $(P=0.00030)$ compared to ESAT- $6_{4-17}$-specific T cells (Fig. 2e). In line with the literature, the vast majority of $\mathrm{KLRG}^{+} \mathrm{T}$ cells coexpressed CX3CR1, which is associated with vascular T cells (24, 25) (Fig. 2f), and therefore in agreement with the data obtained by CD45 iv staining.

In summary, these studies show, by both cytokine production pattern and expression of differentiation markers, that MPT70-specific CD4 T cells are maintained at a lower state of differentiation throughout infection compared to ESAT-6-induced T cells. This difference translates into a higher functional capacity of MPT70-specific CD4 T cells to migrate to infected lung tissue.

The impact of vaccinating with MPT70 is lower than for ESAT-6. The previous data showed that T cells specific for MPT70 were less differentiated than those specific for ESAT-6 during experimental infection. We next investigated the significance of this in the context of vaccine efficacy. Mice were immunized three times with MPT70 or ESAT-6 in the cationic adjuvant formulation 1 (CAF01) adjuvant (35), and immune responses were characterized 2 weeks after the final vaccination. ICS of stimulated splenocytes detected $0.79 \%$ MPT70-specific CD4 T cells compared to $0.42 \%$ for ESAT-6, showing that both antigens were immunogenic and, if anything, MPT70 induced higher responses than ESAT-6 (Fig. 3a). However, 3 weeks after Mtb Erdman challenge, there was a bigger proportion of ESAT-6-specific T cells in the lung compared to MPT70 T cells, indicating earlier expansion/recruitment of ESAT-6-specific T cells (although this was not statistically significant) (Fig. 3b). A characterization of the MPT70- and ESAT-6-specific CD4 T cells showed that there was no difference in T cell differentiation preinfection (Fig. 3c), indicating that there was no intrinsic antigen effect on this parameter. In contrast, a similar analysis postinfection revealed that vaccination with ESAT- 6 had a greater impact on lowering the antigen-specific T cell differentiation in this setting (Fig. 3d). Similar to the observation in Fig. 2a, MPT70-specific T cells had an FDS of around 2.7 during early infection, and vaccination did not change this noticeably. In unvaccinated animals, this level was sustained at week 20 , while vaccination with MPT70 lowered this to 1.1. In contrast, the FDS of ESAT-6-specific T cells remained high throughout infection (6.9 at week 3 and 5.8 at week 20), while vaccination with ESAT-6 resulted in a substantially lower differentiation level around 0.8 to 1.8 throughout the infection (Fig. 3d). These observations were confirmed by KLRG1 staining, which showed a similar pattern to FDS (Fig. S4a). Finally, we determined the protective efficacy by plating lung homogenates. Of note, at weeks 3 to 4 , we observed significant protection of both ESAT-6 $(P<0.0001)$ and MPT70 $(P=0.0001)$, demonstrating the vaccine potential of both antigens (Fig. 3e). However, over the course of four independent experiments, bacterial burdens were lower in ESAT-6-vaccinated animals than MPT70-vaccinated animals ( $P=0.047$ at 3 to 4 weeks postinfection [p.i.]) (Fig. 3e and Fig. S4b).

Taken together, vaccination with ESAT- 6 had the highest impact on T cell differentiation during subsequent infection, and while vaccination with both antigens induced robust protection, there was better protection with ESAT- 6 . Although observed with antigens of different size and immunogenicity, this suggests that in vivo antigen expression could regulate $T$ cell quality as well as protective capacity.

Constitutive expression of MPT70 accelerates $\mathrm{T}$ cell differentiation and improve vaccine protection. To investigate whether $T$ cell differentiation and vaccine protection is directly linked to in vivo antigen transcription, we utilized a recently engineered 
a

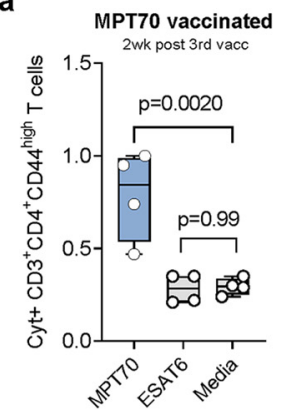

C

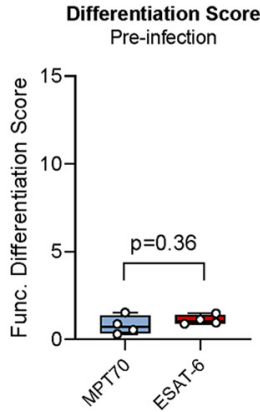

b

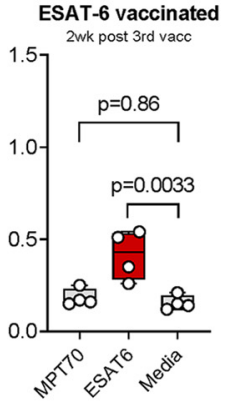

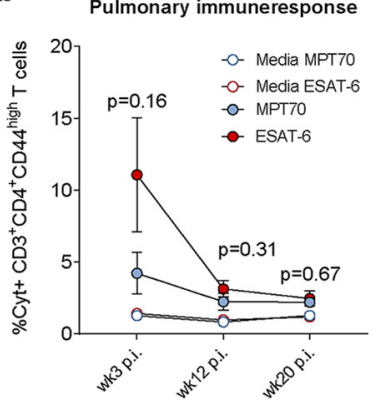

FIG 3 The impact of MPT70 immunization on alleviating infection-driven T cell differentiation is lower than immunization with ESAT-6. Female CB6F1 mice were immunized with either MPT70 or ESAT-6 recombinant protein three times s.c. and challenged with Mtb Erdman 6 weeks after the third immunization. (a) Frequency of MPT70- and ESAT-6-specific CD4 T cells in the spleen 2 weeks after the third vaccination $(n=4)$. Ordinary one-way ANOVA with Dunnett's multiple-comparison test was used to assess statistical differences. (b) Frequency of MPT70- and ESAT-6-specific CD4 T cells in the lung at weeks 3, 12, and 20 after Mtb infection $(n=4)$. Values shown are means \pm SEM. An unpaired $t$ test was used to compare the values for ESAT-6- and MPT70-vaccinated mice. (c) Functional differentiation score (FDS) of MPT70 and ESAT-6-specific CD4 T cells preinfection in the spleen $(n=4)$. An unpaired $t$ test was used to assess statistical differences. (d) FDS of MPT70- and ESAT-6-specific CD4 T cells 3 and 20 weeks after Mtb infection in the lungs of vaccinated mice and mice injected with saline $(n=4)$. Values shown are means \pm SEM. An unpaired $t$ test was used to compare individual time points. Flow cytometry gating is shown as depicted in Fig. S1a, using the antibodies shown in Table 4. (e) The bacterial burden was determined in the lungs of mice injected with saline or mice vaccinated with MPT70 and ESAT-6 3 to 4 weeks after Mtb infection ( $n=26$ to 28). The graph shows the results of four individual experiments (experiment 4 has already been published in reference 29). One-way ANOVA with Tukey's multiple-comparison test was used to assess statistical differences.

H37Rv strain (36) (herein called H37Rv::mpt70 ${ }^{\text {high }}$ ) with significantly increased in vitro expression of MPT70 due to insertion of sigK (Rv0445c) and rskA (Rv0444c) from Mycobacterium orygis $(6,36)$. In line with the previous report $(36)$, we observed that this strain upregulated in vitro expression of MPT70 compared to wild-type (WT) H37Rv, while very little change was observed for the regulators of MPT70 transcription (SigK and RskA) (Fig. 4a). From this, we anticipated that the H37Rv::mpt70 ${ }^{\text {high }}$ strain would have an increased early in vivo expression of MPT70. Transcription analysis of mRNA from lungs of mice 3 weeks after aerosol infection confirmed this, as MPT70 was 6.7-fold higher expressed by mice infected with $\mathrm{H} 37 \mathrm{Rv}:: \mathrm{mpt} 70^{\text {high }}$ than in mice infected with WT H37Rv (Fig. 4b). This analysis also confirmed the observations with Mtb Erdman in Fig. 1a, showing that expression of MPT70 in WT H37Rv was very low at week 3 in contrast to ESAT-6 (Fig. S5a). Of note, complementation of H37Rv did seem to affect the bacterial fitness in vitro (Fig. S5b), which was also associated with a small, but detectable, difference in CFU at day 1 (Fig. 4c). Interestingly, H37Rv::mpt70 ${ }^{\text {high }}$ and WT H37Rv had similar in vivo growth up until week 3, but overexpression of MPT70 seemed to impact long-term persistence negatively (Fig. 4c). We next analyzed the impact on $\mathrm{T}$ cell responses in two independent experiments. Since bacterial load is expected to influence $T$ cell differentiation (21-23), we focused our analysis around week 3 postinfection, where the number of bacteria was the same for WT H37Rv and 


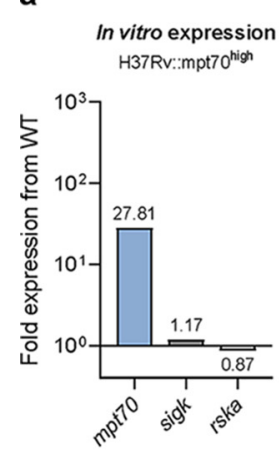

b

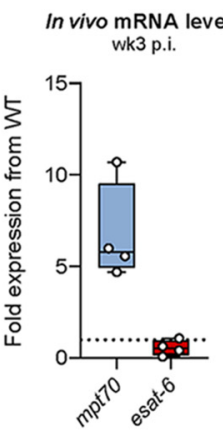

C

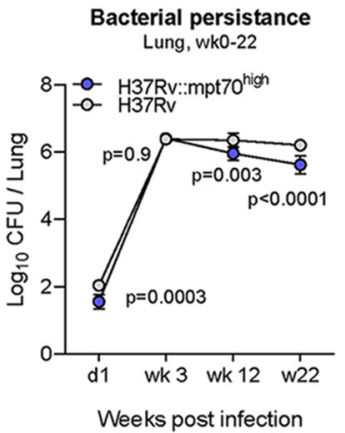

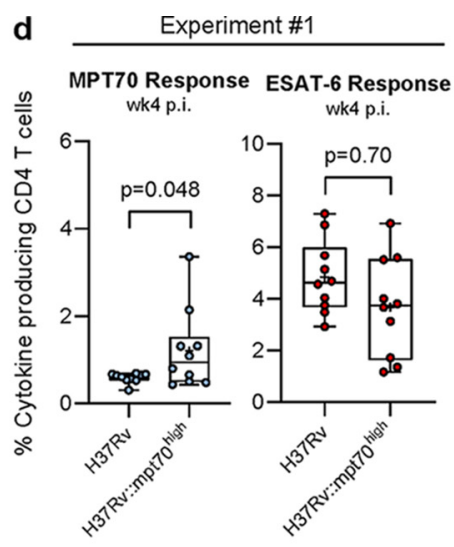

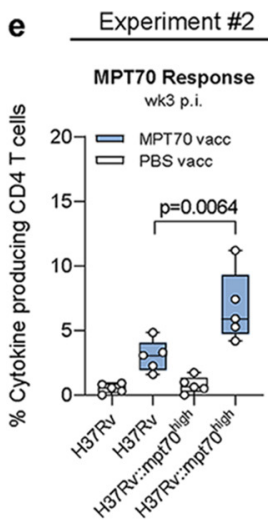

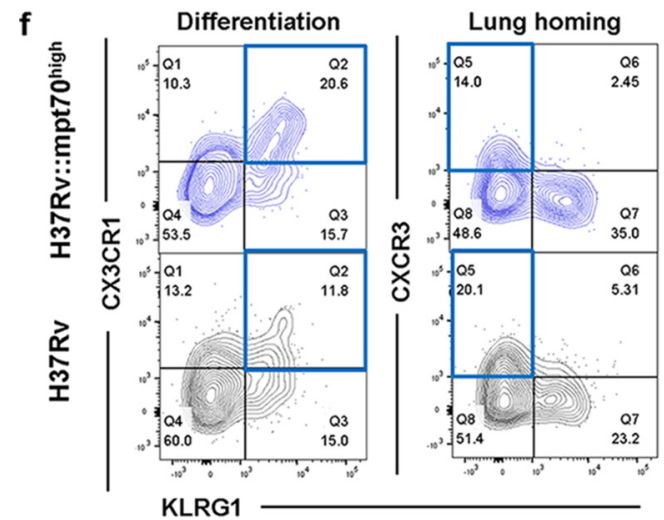
Lung positioning
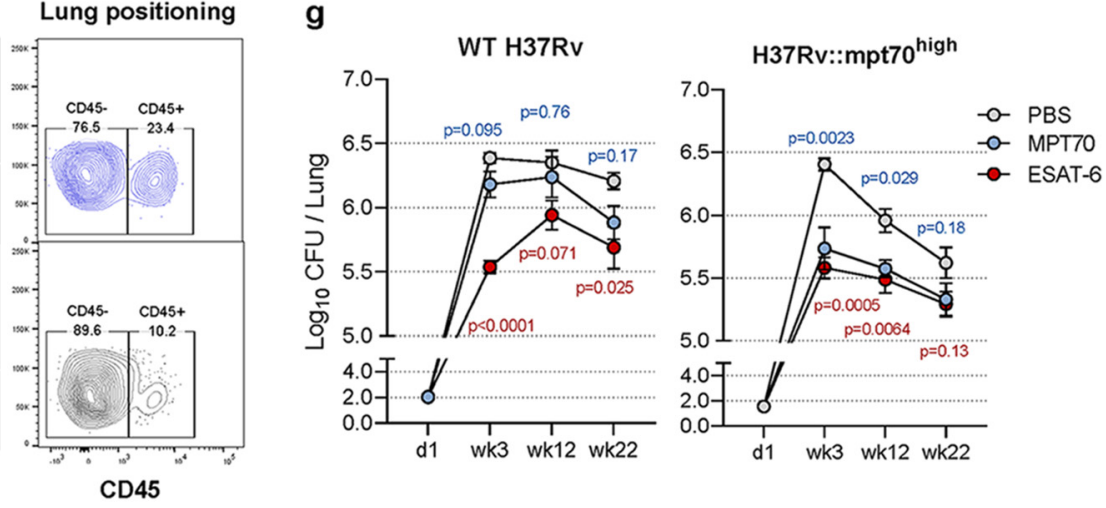

FIG 4 Overexpression of MPT70 accelerates T cell differentiation and increases bacterial susceptibility to MPT70 vaccination. (a) In vitro fold gene expression of sigK, rskA, and MPT70 in H37Rv::mpt70 high compared to WT H37Rv. All genes were tested in technical duplicates and normalized to esxA expression using primers in Table 1. (b) In vivo fold gene expression of MPT70 and ESAT-6 in the lungs of H37Rv::mpt70high-infected mice compared to WT H37Rv-infected mice 3 weeks after Mtb challenge $(n=4)$. Genes were analyzed in technical duplicates using primers and probes in Table 2, normalized to $16 \mathrm{~S}$ rRNA expression, and shown as fold increase from WT H37Rv. A two-tailed, unpaired $t$ test was used to assess statistical differences. (c) Bacterial burden in the lungs of mice injected with PBS at day 1, week 3, week 12, and week 22 after infection with either H37Rv:: mpt70 high or WT H37Rv infection $(n=5)$. Values shown are means \pm SEM. Multiple $t$ tests with correction for multiple testing using the Holm-Sidak method were used to assess statistical differences. (d) Frequency of lung MPT70- and ESAT-6-specific CD4 T cells 4 weeks after Mtb infection $(n=10)$. Box plots with whiskers indicating the minimum and maximum values are shown. The mean values are indicated with + symbols. A unpaired, two-tailed $t$ test was used to assess statistical differences. (e) Frequency of lung MPT70-specific CD4 T cells 3 weeks after Mtb infection in mice injected with PBS (white boxes) and mice vaccinated with MPT70 (blue boxes) $(n=5)$. A unpaired, two-tailed $t$ test was used to assess statistical differences. (f) Representative concatenated FACS plots ( $n=10$ ) showing the expression of CX3CR1, CXCR3, KLRG1, or CD45 on MPT70-specific CD4 T cells 4 weeks after H37Rv:: mpt70high infection (blue) or H37Rv infection (gray). Flow cytometry gating is shown as depicted in Fig. S1a, using antibodies shown in Table 5. (g) Bacterial numbers were determined in the lungs of mice vaccinated with PBS or mice vaccinated with MPT70 and ESAT-6 at day 1, week 3, week 12, and week 22 after WT H37Rv infection (left) or H37Rv::mpt70 high infection (right) ( $n=4$ to 5). One mouse was excluded from the week 12 time point (H37Rv::mpt70 high, MPT70 vaccinated), as the mouse was very sick, had high weight loss, and met the study's predefined humane endpoints ( $P$ value $=0.67$, if included). Values shown are means \pm SEM. Statistical differences were assessed using one-way ANOVA with Tukey's multiple-comparison test.

H37Rv::mpt70 high. The first experiment demonstrated that the CD4 T cell response against MPT70 was significantly increased in mice infected with H37Rv::mpt70 high compared to WT H37Rv (Fig. 4d). For comparison, ESAT-6 responses did not differ between the two strains (Fig. 4d). In agreement with this observation, a second experiment showed that the response to MPT70 vaccination was increased in mice infected with H37Rv::mpt70 high ( $P=0.0064)$ compared to WT-infected mice (Fig. 4e). We then asked whether the early expression and elevated MPT70 immune response accelerated CD4 $T$ cell differentiation and altered expression of markers associated with lung homing. CXCR3 is primarily expressed on lung-homing T cells $(25,26)$, whereas CX3CR1 is associated with T cells in the vasculature (37). Studying these surface markers on MPT70specific CD4 $\mathrm{T}$ cells revealed a substantially higher proportion of $\mathrm{CX} 3 \mathrm{CR} 1{ }^{+} \mathrm{KLRG} 1^{+} \mathrm{T}$ cells after H37Rv::mpt70 ${ }^{\text {high }}$ infection (20.6\%) compared to H37Rv infection (11.8\%), indicating increased differentiation and decreased lung homing capacity for H37Rv:: mpt70 high-primed MPT70 CD4 T cells (Fig. 4f). This was also evident in a vaccination setting, as MPT70 immunization induced the biggest reduction of $\mathrm{CX} 3 \mathrm{CR} 1^{+} \mathrm{KLRG}^{+} \mathrm{T}$ cells 
after H37Rv::mpt70 high infection (Fig. S5c). In contrast, the frequency of CX3CR1 $1^{+} \mathrm{KLRG} 1^{+}$ ESAT-6 T cells was not different between the strains, demonstrating that the increased T cell differentiation was a specific effect of MPT70 overexpression (Fig. S5d). In line with increased MPT70-specific T cell differentiation, a lower frequency of CXCR3-expressing

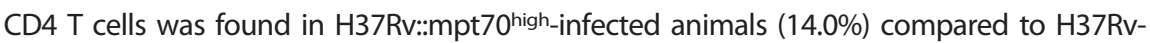
infected animals (20.1\%), which also correlated with a higher proportion of CD45-labeled MPT70 CD4 T cells located in the lung-associated vasculature (23.4\% to $10.2 \%$ ) (Fig. 4 f). Together, the immune data showed that increased early in vivo expression altered the MPT70-specific immune responses to resemble those of ESAT- 6 after WT Mtb infection. We finally addressed whether vaccine-induced protection of MPT70 was increased if mice were challenged with the H37Rv::mpt70high strain. Immunized mice were challenged with either WT H37Rv or H37Rv::mpt70 high, and bacterial numbers were determined in the lungs at weeks 3, 12, and 22. Consistent with data from Mtb Erdman (Fig. 3e), MPT70 vaccination conferred less protection than ESAT-6 against challenge with WT H37Rv (Fig. 4g). In contrast, MPT70 vaccination induced a substantial reduction in bacterial load at all time points in mice challenged with H37Rv::mpt70high, providing protection that was comparable to protection by ESAT-6.

Taken together, overexpression of MPT70 increased MPT70 vaccine protection substantially, indicating that in vivo antigen expression kinetics regulates vaccine protection rather than properties of the antigen as such. This, even though high antigen expression resulted in increased $T$ cell differentiation. Vaccination with highly expressed antigens therefore requires that the vaccine primes $T$ cells of a low differentiation.

\section{DISCUSSION}

CD4 T cell differentiation is a key determinant of protective immunity against Mtb $(21,38,39)$, and antigen load is described to influence T cell development (21-23). Importantly, during the course of infection, Mtb adapts to the changing environment of the host, and it is poorly described how differential in vivo antigen expression influences CD4 T cell responses and vaccine potential. In this study, we compared ESAT-6, which is a well-known constitutively expressed antigen $(32,33)$, to MPT70 that is expressed at negligible amounts in vitro but inducible upon IFN- $\gamma$ activation $(5,6)$ or nutrient deprivation (8) in infected macrophages. After murine aerosol infection, we observed that MPT70 immune recognition was delayed compared to ESAT-6, which correlated with lower initial antigen expression of MPT70. This is in line with a previous genome-wide microarray study after H37Rv infection in BALB/c mice, where MPT70 expression gradually increases from day 7 to 28 , where it is similar to ESAT-6 (40). Based on this, it can be speculated that in vivo expression of MPT70 is upregulated in response to host adaptive immune responses, which occur around weeks 2 to 3 in mice $(41,42)$. This likely places MPT70 in the same functional category as the stressinduced genes encoded by the dormancy survival regulon (DosR) that likewise are upregulated in chronically infected mice and IFN- $\gamma$-treated macrophages $(5,43)$.

Given that antigen availability influences $T$ cell quality, we asked how the delayed antigen recognition of MPT70 would impact the CD4 T cell response. In mice infected with WT Mtb Erdman, we observed that MPT70-specific CD4 T cells had a significantly lower differentiation status than ESAT- 6 based on the expression of KLRG1, CXCR3, CX3CR1, and T-bet as well as cytokine expression pattern. This is in line with our most recent results, showing that MPT70 is highly immunogenic during late chronic infection, but with an altered T cell phenotype compared to ESAT-6 (29). Having established associations between antigen expression and $T$ cell quality, we investigated whether there was a causal relationship. For this, we utilized a newly described H37Rv strain, which has high in vitro expression of MPT70 due to a gene insert of the regulators sigK (Rv0445c) and rskA (Rv0444c) from M. orygis (36). Importantly, we observed that infection with this strain significantly increased the differentiation state of the MPT70-specific CD4 T cells and diminished their ability to enter the infected lung tissue. No 
differences were observed for ESAT-6-specific CD4 T cells, demonstrating that this was a specific consequence of overexpressing MPT70. These data therefore indicate that the quality of infection-driven T cells is dictated by the in vivo antigen expression profile. This is in line with the study by A. Moguche et al., demonstrating that in vivo overexpression of Ag85B significantly increased CD4 T cell differentiation (22). Given that Ag85B expression is downregulated early during infection (32), in contrast to MPT70, these studies collectively suggest that CD4 T cell differentiation is a result of the cumulative antigen exposure, and that highly and constitutively expressed antigens would have the highest degree of $\mathrm{T}$ cell differentiation.

We finally examined the link between antigen expression and protective capacity in a vaccination setting. Antigens expressed during late-stage Mtb infection have been the focus of multistage TB vaccines as they may specifically target bacteria during latency $(16,44-46)$, and the expression profile of MPT70 could make this an interesting candidate. After vaccination, both MPT70 and ESAT-6 induced robust protection against Mtb Erdman infection, which is in line with other studies reporting high vaccine potential of these two antigens $(13,15,29,30)$. However, despite lower immunogenicity, ESAT- 6 vaccination induced the highest protection. Although ESAT- 6 and MPT70 are different in both size, epitope pattern, and immunogenicity, this observation prompted us to hypothesize that constitutive in vivo antigen expression is optimal for vaccine protection. To investigate this more directly, we compared the effect of immunization with MPT70 against WT H37Rv or H37Rv::mpt70 high where MPT70 is overexpressed. Here we observed that the MPT70-mediated protection was significantly increased against the H37Rv::mpt70 high strain, where ESAT- 6 and MPT70 performed similarly, compared to the WT H37Rv strain. Together with the T cell analysis, these data suggest that constitutively expressed antigens are superior vaccine antigens, supposedly because of increased antigen "visibility" by the infected macrophages, but due to continuously high antigen presence, the infection-driven $\mathrm{T}$ cells are also pushed toward terminal differentiation and decreased functionality. We speculate that this could be a survival strategy by Mtb (47) and show how targeted vaccination with adjuvanted proteins can compensate for this by priming (and maintaining) less differentiated T cells (29). Although the mechanisms behind this are unknown, previous data confirm that immunization with Mtb proteins in the CAF01 adjuvant induces CD4 T cells of low differentiation as well as Th17/Th17-like T cells that are maintained during Mtb infection $(41,48,49)$. Although this somewhat contrasts with data for memory CD8 T cells (50), CD4 T cell plasticity is maximal at early stages of differentiation, and it has been shown that Th17 cells and less differentiated Th17-like T cells share many features with stem cells and have the capacity to persist over longer periods of time $(48,51-53)$. Together, these features could potentially explain the observed ability of CAF01induced CD4 T cells to resist infection-driven T cell differentiation, which will be an important research topic of the future.

Importantly, we investigated only the impact of vaccination after single antigen immunization, and it can be speculated that MPT70, and similar antigens, might perform differently in larger fusions proteins. Here, the accelerated adaptive immune responses offered by other antigens, like ESAT-6 (41), may trigger earlier expression of MPT70, which in turn would increase the MPT70-mediated protection against Mtb. Additionally, MPT70 is naturally overexpressed in the animal-adapted Mycobacterium strains; M. orygis, M. caprae, and M. bovis (6), which could imply that an MPT70-containing vaccine would be particularly efficacious against pathogens causing TB in livestock.

The course of chronic infection mimicked in the mouse model is in many ways different from the human Mtb infection that can last for years and display distinct features in granuloma structure and environment (54). In fact, in nonhuman primates (NHPs), it has been reported that very few of the Mtb-specific CD4 T cells are terminally differentiated, and in contrast to mice, almost all of the Mtb-specific cells are found in the lung parenchyma (55). This could lead to the interpretation that T cell differentiation is of less importance in NHPs compared to mice. However, it has been shown that 
a vaccine induction of less differentiated central memory $\mathrm{T}$ cells is associated with increased protection in NHPs (56), and so far, it has not been studied whether terminal T cell differentiation occur in NHPs after long-term infection (i.e., after day 49). Indeed, in humans, the degree of CD4 T cell differentiation is increased in people with active disease compared to latent tuberculosis infection (57-59), indicating that progression of infection drives T cell differentiation. Furthermore, increased Mtb-specific CD4 T cell differentiation has been associated with increased tissue pathology in TB patients (60). Together, these studies support that T cell differentiation is an important feature of the protective response in humans, even if defective T cell homing is not part of the explanation. This warrants further validation of our results in higher animal models and/or humans.

Besides host species, there may also be differences in antigen expression levels between clinical Mtb isolates that are known to display some level of genetic diversity and virulence variability (61), and future studies should extrapolate our results to other relevant isolates. Of note, MPT70 has been described as part of the "core transcriptome" in macrophage phagosomes with conserved expression and regulation across all MTBC isolates (62), suggesting that in vivo MPT70 expression will not vary between clinical Mtb isolates. Overexpression of MPT70, however, did seem to impact the bacterium's overall capability to persist after week 3 , implicating that abundant MPT70 is not advantageous for Mtb during chronic infection. This has also been seen in a similar study overexpressing Mtb heat shock proteins (63) and might be CD4 T cell dependent as has been reported for an Ag85B-overexpressing strain (64).

Overall, our study provides new insights into host-pathogen interactions and describes how in vivo antigen expression kinetics can regulate $T$ cell functionality and vaccine protection. Data show that high antigen expression drives T cells toward terminal differentiation and that targeted preventive vaccination can counteract this effect. We also demonstrate that highly expressed antigens are optimal vaccine targets and accentuate that $T$ cell differentiation can be used as a new way to identify the most promising antigens. This has implications for rational vaccine design, and future preclinical and clinical studies could use antigen-specific T cell differentiation as a readily measurable proxy for high in vivo antigen expression.

\section{MATERIALS AND METHODS}

Mice. Six- to 8-week-old female CB6F1 mice (BALB/C $\times$ C57BL/6; Envigo) or C57BL/6 mice (Jackson Laboratory) were purchased. Mice were randomly assigned to cages of five to eight on the day of arrival. Before initiating the experiment, mice had at least 1 week of acclimation. Mice were housed in biosafety level 2 (BSL II) in individually ventilated cages (Scanbur, Denmark) and had access to nesting material as well as enrichment. During the course of the experiment, mice were fed with irradiated Teklad global $16 \%$ protein rodent diet (Envigo, catalog no. 2916C) and had access to water ad libitum. On the day of challenge, cages with mice were transferred to BSL-III where they were housed until termination of the experiment.

Ethics. All experimental protocols were initially reviewed and approved by a local ethical committee at Statens Serum Institut (SSI) and by the Facility Animal Care Committee at the Research Institute of McGill University Health Center (RI-MUHC) (project identifier [ID] 2015-7656). Experimental procedures were conducted in accordance with the regulations set forward by the Danish Ministry of Justice, Canadian Council of Animal Care (CCAC), and Animal Protection Committees under license permit no. 2019-15-0201-00309 and in compliance with the European Union Directive 2010/63/EU.

Recombinant proteins and immunizations. The following recombinant antigens were expressed and purified as previously described (29): ESAT-6 (Rv3875) or MPT70 (Rv2875). Mice were immunized three times subcutaneously (s.c.) at the base of the tail or neck at 2-week intervals with either recombinant ESAT-6 or MPT70. Recombinant proteins were diluted in Tris-HCl buffer plus $9 \%$ trehalose $(\mathrm{pH} \mathrm{7.2)}$ and adjuvanted with cationic adjuvant formulation 1 (CAF01) consisting of dimethyldioctadecylammonium (DDA) and trehalose dibehenate (TDB) at a ratio of $250 \mu \mathrm{g}$ DDA per/50 $\mu \mathrm{g}$ TDB (35). As a control, mice were vaccinated with phosphate-buffered saline (PBS).

Mtb infections and CFU enumeration. Mtb Erdman (ATCC 35801/TMC107) was cultured in Difco Middlebrook 7H9 (Becton Dickinson [BD]) supplemented with 10\% BBL Middlebrook ADC Enrichment (BD) for 2 to 3 weeks using an orbital shaker $\left(\sim 110 \mathrm{rpm}, 37^{\circ} \mathrm{C}\right)$. Bacteria were harvested in log phase and stored at $-80^{\circ} \mathrm{C}$ until use. Before use in the experiment, the concentration of the bacterial stock was determined by plating in triplicate. For aerosol infections, the vial of Mtb was thawed, sonicated for 5 min, thoroughly suspended with a 27 -gauge $(27 \mathrm{G}$ ) needle to remove clumps, and mixed in PBS to the 
TABLE 1 Primers used for in vitro gene expression analyses

\begin{tabular}{lll}
\hline & Primer sequence & \\
\cline { 2 - 3 } Gene & Forward primer $\left(\mathbf{5}^{\prime}-\mathbf{3}^{\prime}\right)$ & Reverse primer $\left(\mathbf{5}^{\prime} \mathbf{-} \mathbf{3}^{\prime}\right)$ \\
\hline sigk & GGTGGGCCATGGTCAAAA & AGTTGACTCCGCCAAAGGT \\
rskA & ACACAGGTCTGCTGGTGATG & TCGACGGTGAATGCCAGTG \\
$m p t 70$ & CCTCGAACAATCCGGAGTT & GTAGACACCCCACCACAGAC \\
esat-6 & CAGAGCAGCAGTGGAATTCG & CATTTTGCTGGACACCCTGG \\
sigA & ATCGCGCGAAAAACCATCTG & CACCGACTGCAGTTGATCCT \\
\hline
\end{tabular}

desired concentration. Mice were challenged with $0.5 \times 10^{6} \mathrm{CFU} / \mathrm{ml}$ (around 50 to $100 \mathrm{CFU}$ ) Mtb Erdman by the aerosol route using a Biaera exposure system controlled via AeroMP software.

The Mtb Pasteur H37Rv, Pasteur H37Rv::mpt70 high (rskA and sigK of M. orygis) (36), and Pasteur $\mathrm{H} 37 \mathrm{Rv}: \mathrm{Rv}$ ( $r$ skA and sigK of $M$. tuberculosis) (36) strains were grown in Middlebrook $7 \mathrm{H} 9$ medium (Difco Laboratories) supplemented with 0.05\% Tween 80 (Sigma-Aldrich), 0.2\% glycerol, 10\% ADC Enrichment (BD) in a rolling incubator at $37^{\circ} \mathrm{C}$. The bacterial cultures were passaged twice, adjusted to an optical density at $600 \mathrm{~nm}\left(\mathrm{OD}_{600}\right)$ of 0.5 , pelleted, resuspended in glycerol, and subsequently frozen at $-80^{\circ} \mathrm{C}$. On the day of the experiment, vials were thawed, thoroughly resuspended with a $27 \mathrm{G}$ needle, and adjusted to an OD of 0.05 in PBS (approximately 50 CFU). Mice were challenged with an aerosol infection using a $\mathrm{CH}$ Technologies nose-only inhalation exposure system with 15-min exposure, up to 18 mice per run. Mice euthanized for each experimental time point were in the same aerosol run.

To enumerate bacteria in the lungs of mice after infection, left lobes from individual mice were homogenized with GentleMACS M-tubes (Miltenyi Biotec) in $3 \mathrm{ml}$ MilliQ water containing PANTA antibiotic mixture (BD, catalog no. 245114) or with an Omni Tissue Homogeniser and Hard Tissue Omni Tip Plastic Homogenising Probes (Omni International) in a 50-ml tube containing $1 \mathrm{ml} 7 \mathrm{H} 9$ supplemented medium. The homogenate was serially diluted, plated, and grown on $7 \mathrm{H} 11$ plates (BD) or $7 \mathrm{H} 10$ plates containing PANTA for approximately 2 to 3 weeks at $37^{\circ} \mathrm{C}$ and $5 \% \mathrm{CO}_{2}$. CFU were counted, log transformed to normalize data, and shown as $\log _{10}$ CFU per the whole lung. Whenever possible, a cutoff of 10 colonies was set to minimize variability and errors due to plating.

In vitro growth assay. The growth of Mtb H37Rv, Mtb H37Rv::mpt70high, and H37Rv::Rv in 7H9 medium (supplemented as described above) was monitored with a spectrophotometer at $\mathrm{OD}_{600}$ in triplicates every $24 \mathrm{~h}$ for 4 days. The culture flasks were incubated at $37^{\circ} \mathrm{C}$ under rotating conditions.

In vitro and in vivo Mtb RNA extractions. For in vitro RNA extractions, Mtb H37Rv and H37Rv:: $m p t 70^{\text {high }}$ were passaged twice and adjusted to an $\mathrm{OD}_{600}$ of 0.2 to 0.5 . The bacteria were pelleted and resuspended in $1 \mathrm{ml}$ TRIzol reagent (Invitrogen, catalog no. 15596026). For in vivo RNA extractions, the postcaval lung lobes of Mtb-infected mice were harvested aseptically and immediately stored at $-80^{\circ} \mathrm{C}$ in $1 \mathrm{ml}$ RNA later (Qiagen, catalog no./ID: 76106) until further processing. The lung tissues were mechanically disrupted in $1 \mathrm{ml}$ TRlzol reagent using lysing matrix D or E tubes (MP Biomedicals, stock-keeping unit [SKU] 116913050-CF, SKU 116914050-CF) and a FastPrep-24 bead beater (MP, SKU 116004500). The grinded lung tissues were stored at $-80^{\circ} \mathrm{C}$ until further processing. On the day of RNA extraction, the lung tissues were bead beated with $0.1-\mathrm{mm}$ zirconia/silica beads three times at $6.5 \mathrm{~m} / \mathrm{s}$ for $30 \mathrm{~s}$ with 3$\mathrm{min}$ rest on ice in between runs. The beads were pelleted by centrifuging at 12,000 $\times g$ for $1 \mathrm{~min}$, and the TRIzol layer was moved to a fresh tube containing chloroform isoamyl alcohol (24:1). After centrifuging at $12,000 \times g$ for $15 \mathrm{~min}$ at $4^{\circ} \mathrm{C}$, the top aqueous phase was transferred and precipitated with $3 \mathrm{M}$ sodium acetate and isopropanol for at least $2 \mathrm{~h}$ or overnight at $-20^{\circ} \mathrm{C}$. The pellet was washed twice in ethanol, air dried, and resuspended in RNase-free water. A cleanup step was performed with RNA Easy minikit (Qiagen), followed by a minimum of three DNase treatments (Ambion, catalog no. AM1907). The RNA purity and concentration were measured by spectrophotometry (Tecan Infinite M200 Pro plate reader) or using the RNA Qubit assay (Invitrogen, catalog no. Q32852). RNA samples were checked for remaining genomic DNA by PCR using the SigA primers. A total of 300 to 1,000 ng RNA was reverse transcribed (Thermo Scientific, catalog no. K1621); a minus reverse transcriptase control was included for every sample.

Real-time qPCR and gene expression analysis. To determine in vitro mRNA levels of MPT70, SigK, RskA, and ESAT-6, we performed a reverse transcription-quantitative PCR (RT-qPCR) using Maxima SYBR green kit (Thermo Scientific, catalog no. K0223) with the use of the following primers (Table 1). mRNA levels were normalized to EsxA and fold gene expression from Mtb H37Rv was plotted as $2^{-\Delta c t}$.

In vivo mRNA levels were measured with qRT-PCR using dually labeled probes (Eurofins) (Table 2). All probes and primers were diluted to a final concentration of $250 \mathrm{nM}$ (probes) and $900 \mathrm{nM}$ (primers), respectively, and mixed with either iTaq Universal Probe Supermix (Bio-Rad, catalog no. 1725130) or SsoAdvanced Universal Probes Supermix (Bio-Rad, catalog no. 1725281). All cDNA samples were prediluted 10 times in diethyl pyrocarbonate (DEPC)-treated water and used in a final dilution of 1:40 in the reaction. Thermal cycling protocol was programmed according to the manufacturer's instructions for low abundant targets $\left(45 \mathrm{cycles}\right.$ with $1 \mathrm{cycle}$ consisting of $30 \mathrm{~s}$ at $95^{\circ} \mathrm{C}, 10 \mathrm{~s}$ at $95^{\circ} \mathrm{C}$, and $1 \mathrm{~min}$ at $60^{\circ} \mathrm{C}$ ). For gene expression analysis throughout Mtb Erdman infection (Fig. 1a), average quantification cycle $\left(C_{a}\right)$ values for each sample were normalized to $16 \mathrm{~S}$ rRNA and shown as relative mRNA levels $\left(2^{-\Delta C q}\right)$. The fold gene expression of $m p t 70$ and esat- 6 in H37Rv::mpt70 high from WT H37Rv were calculated with the 
TABLE 2 Primers and probes used for in vivo gene expression analyses

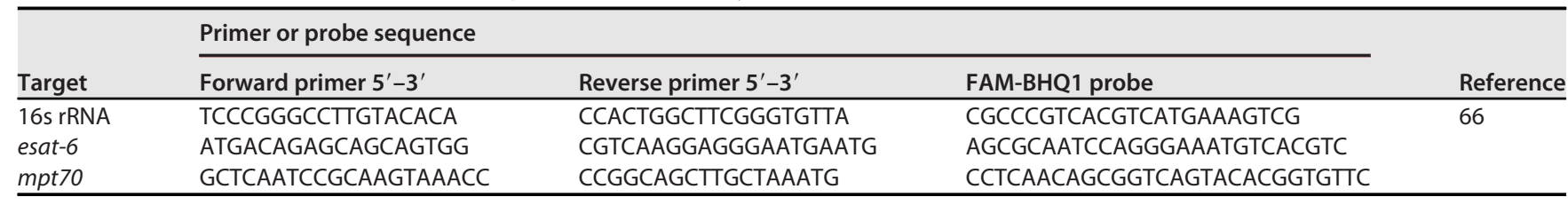

$2^{-\Delta \Delta C T}$ method with normalization to $16 \mathrm{~S}$ rRNA (Fig. 4b). For every run, a no-template control, negative control (naive mouse), and positive controls (genomic DNA of H37Rv and BCG) were included.

In vivo labeling of intravascular CD4 T cells. Mice were anesthetized with isoflurane and injected intravenously with 2.5 to $5.0 \mu \mathrm{g}$ fluorescein isothiocyanate (FITC)-labeled CD45 antibody (BD Pharmingen, clone 104; catalog no. 553772) diluted in 100 to $250 \mu \mathrm{l} \mathrm{PBS}$. Three minutes after injection, mice were euthanized by cervical dislocation, and organs were aseptically harvested for further processing as described below.

Preparation of single-cell suspensions. Spleens or lungs were aseptically harvested from euthanized mice. Lungs were first homogenized in Gentle MACS tubes C (Miltenyi Biotec) or chopped into small pieces using scalpels, followed by $1 \mathrm{~h}$ of collagenase digestion (Sigma-Aldrich; catalog no. C5138) at $37^{\circ} \mathrm{C}$ and $5 \% \mathrm{CO}_{2}$. The lung homogenate and spleens were forced through $70-$ to $100-\mu \mathrm{m}$ cell strainers (BD Biosciences) with the stopper from a $5-\mathrm{ml}$ syringe (BD) and washed twice with cold RPMI medium (Gibco; RPMI 1640) by centrifuging $5 \mathrm{~min}$ at $1,800 \mathrm{rpm}$. A red blood cell lysis step was performed in between washes (Roche, catalog no. 11814389001). Cells were finally resuspended in enriched RPMI medium (RPMI 1640, 10\% heat-inactivated fetal calf serum (FCS) (Biochrom GmbH), 10 mM HEPES (Invitrogen), $2 \mathrm{mM}$ L-glutamine (Invitrogen), $1 \mathrm{mM}$ Natriumpyruvate (Invitrogen), $1 \times$ nonessential amino acids (MP Biomedicals, LLC), $5 \times 10^{5} \mathrm{M}$ 2-mercaptoethanol (Sigma-Aldrich), and penicillin-streptomycin (Gibco). Cells were counted using an automatic Nucleocounter (Chemotec) and adjusted to $2 \times 10^{5}$ cells/well for enzyme-linked immunosorbent assay (ELISA) and $1 \times 10^{6}$ to $2 \times 10^{6}$ cells/well for flow cytometry.

Design of an MHC-II tetramer specific for MPT70. Splenocytes of MPT70-vaccinated mice were restimulated in the presence of overlapping 15-mer peptides, and two murine epitopes were identified (29). The recognized peptides corresponded to amino acid (aa) positions 37 to 53 and 93 to 109 in MPT70. These epitopes were further epitope mapped in vaccinated mice with peptides varying 1 aa in length to identify the minimal core epitope which is the minimal number of amino acids necessary for $T$ cell recognition (see Fig. S2a in the supplemental material). We found EYAAANPTGPA and FAPTNAAF as the core epitopes, but as FAPTNAAF was not highly recognized by Mtb-infected mice (data not shown), it was not further characterized. As the optimal peptide length for an MHC-II tetramer may vary between 11 and 16 aa, different peptide lengths extending the core epitope were tested with no big difference in response magnitude as long as the sequence "YAAANPTGP" was present (Fig. S2b). On the basis of these results, we designed a tetramer specific for $\mathrm{I}^{-\mathrm{A}^{\mathrm{b}}: \mathrm{MPT70}_{38-52}}$ (CAEYAAANPTGPAS). This epitope has previously been identified in MPB70 DNA-immunized C57BL/6 H-2 ${ }^{\mathrm{b}}$ and B6D2 (F1) $\mathrm{H}-2 \mathrm{~d}^{\mathrm{b}}$ mice in an enzymelinked immunosorbent spot (ELISPOT) assay with no humoral response detected in mice of haplotype $\mathrm{H}$ $2^{\mathrm{d}}(65)$.

MHC-II tetramer staining. Tetramers (MPT70 ${ }^{38-52}: 1-A b$, ESAT-6 ${ }^{4-17}: 1-\mathrm{Ab}$ ) conjugated to BV421 or phy-

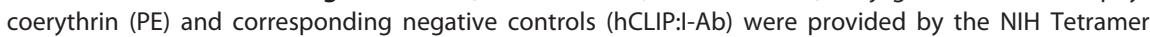
Core Facility (Atlanta, GA, USA). MHC-II tetramers were titrated and tested for optimal staining conditions before the experiment. Single-cell suspensions were stained with tetramers diluted 1:50 in fluores-

TABLE 3 Antibodies used for tetramer characterization in Fig. 2

\begin{tabular}{llllll}
\hline Antibody & Fluorophore & Supplier & Clone & Dilution & Catalog no. \\
\hline CD3 & Bv650 & Biolegend & 17A2 & $1: 100$ & 100229 \\
CD4 & Bv510 & Biolegend & RM4-5 & $1: 400$ & 100559 \\
Viability & efluor780 & eBioscience & & $1: 1000$ & \\
CXCR3 & PerCpCy5.5 & eBioscience & CXCR3-173 & $1: 100$ & $45-1831-82$ \\
CX3CR1 & Bv785 & Biolegend & SAO11F11 & $1: 100$ & 149029 \\
CD44 & Alx700 & Biolegend & IM7 & $1: 200$ & 103026 \\
KLRG1 & Bv711 & Biolegend & 2F1 & $1: 100$ & 138427 \\
CD45 (in vivo) & FITC & BD Bioscience & 104 & $1: 50$ & 553772 \\
T-bet & PE-Cy7 & eBioscience & 4B10 & $1: 100$ & $25-5825-82$ \\
hClip Control & Bv421 & NIH & & $1: 50$ & \\
MPT70 tet & Bv421 & NIH & & $1: 50$ & \\
hClip Control & PE & NIH & & $1: 50$ & \\
E6 tet & PE & NIH & & $1: 50$ & \\
\hline
\end{tabular}


TABLE 4 Antibodies used for T cell characterization in Fig. 1, 2, and 3

\begin{tabular}{llllll}
\hline Antibody & Fluorophore & Supplier & Clone & Dilution & Catalog no. \\
\hline CD3 & Bv650 & Biolegend & 17A2 & $1: 100$ & 100229 \\
CD4 & Bv510 & Biolegend & RM4-5 & $1: 400$ & 100559 \\
CD44 & Alx700 & Biolegend & IM7 & $1: 200$ & 103026 \\
KLRG1 & Bv711 & Biolegend & 2F1 & $1: 100$ & 138427 \\
PD-1 & Bv421 & Biolegend & 29F.1A12 & $1: 100$ & 135218 \\
IL-2 & APC-Cy7 & BD Bioscience & JES6-5H4 & $1: 100$ & 560547 \\
IL-17 & PerCpCy5.5 & eBioscience & XMG1.2 & $1: 200$ & $45-7177-82$ \\
TNF- $\alpha$ & PE & eBioscience & MP6-XT22 & $1: 200$ & $12-7321-82$ \\
IFN-y & PE-Cy7 & eBioscience & XMG1.2 & $1: 200$ & $25-7311-82$ \\
CD45.2 & FITC & BD Bioscience & 104 & $1: 50$ & 553772 \\
\hline
\end{tabular}

cence-activated cell sorting (FACS) buffer (PBS plus 1\% FCS) containing 1:200 Fc block (anti-CD16/CD32) for $30 \mathrm{~min}$ at $37^{\circ} \mathrm{C}$. The MPT70 $0^{38-52} \mathrm{MHC}-1 /$ tetramer was specifically developed for this study (Fig. S2).

In vitro restimulation and intracellular cytokine staining. For intracellular cytokine staining (ICS), cells were restimulated with $2 \mu \mathrm{g} / \mathrm{ml}$ antigen or medium in the presence of $1 \mu \mathrm{g} / \mathrm{ml}$ anti-CD28 (clone 37.51) and anti-CD49d (clone 9C10-MFR4.B) in 96-well V-bottom TCT microtiter plates (Corning; catalog no. 3894) for $1 \mathrm{~h}$ at $37^{\circ} \mathrm{C}$ and $5 \% \mathrm{CO}_{2}$. Restimulation with ionomycin in conjunction with phorbol myristate acetate (PMA) was included as a positive control. Subsequently, $10 \mu \mathrm{g} / \mathrm{ml}$ Brefeldin A was added to each well (Sigma-Aldrich; catalog no. B7651) (5 mg) and followed by another 5- to 6-h incubation at $37^{\circ} \mathrm{C}$ and $5 \% \mathrm{CO}_{2}$, after which cells were kept at $4^{\circ} \mathrm{C}$ until staining or immediately surface stained and fixed.

Prior to staining, cells were washed with FACS buffer and subsequently stained surface markers diluted in brilliant stain buffer (BD Horizon; catalog no. 566349) using antibodies indicated in Tables 3, 4, and 5. Fixation and permeabilization were performed using the Fixation/Permeabilization Solution kit (BD Cytofix/Cytoperm; catalog no. 554714) or Foxp3/Transcription Factor Staining Buffer Set (eBioscience; catalog no. 00-5523-00) per the manufacturer's instructions followed by intracellular staining with anti-IFN$\gamma$, anti-IL-2, anti-TNF- $\alpha$, and anti-IL17A and/or transcription factor staining with anti-T-bet. Fluorescence minus one controls were performed for CD3, CD44, KLRG1, PD-1, CXCR3, CX3CR1, IL-2, IL-17, IFN- $\gamma$, and Tbet on pooled cells to set boundary gates for surface, intracellular, and transcription factor markers. Gating strategies for defining tetramer-positive CD4 T cells and cytokine-producing CD4 T cells are exemplified in Fig. S3 (tetramer) and Fig. S1 (ICS).

IFN $-\gamma$ sandwich ELISA. Splenocytes or lung cells were adjusted to a cell concentration of $2 \times 10^{5}$ cells/well and restimulated in the presence of recombinant protein or peptides in round-bottom plates for 3 days as previously described (29). A sandwich ELISA was performed on the culture supernatants to determine the concentration of total IFN- $\gamma$. In brief, microtiter plates were coated with primary IFN- $\gamma$ antibody, blocked with $2 \%$ skim milk, and incubated overnight with prediluted supernatants. IFN- $\gamma$ was detected with a secondary IFN- $\gamma$ antibody, followed by a horseradish peroxidase (HRP)-conjugated antibody, and the reaction was developed using 3,3',5,5'-tetramethylbenzidine (TMB) substrate (TMB Plus; Kementec). Plates were read at $450 \mathrm{~nm}$ with $620-\mathrm{nm}$ background correction using an ELISA reader (Tecan Sunrise).

Statistical analyses. Cells from the murine studies were analyzed using a BD LRSFortessa or BD LRSFortessa X20, and the forward scatter (FSC) files were afterwards manually gated with FlowJo v10

TABLE 5 Antibodies used for T cell characterization in Fig. 4.

\begin{tabular}{llllll}
\hline Antibody & Fluorophore & Supplier & Clone & Dilution & Catalog no. \\
\hline Viability & 440UV & BD Horizon & & $1: 1,000$ & 566332 \\
CD8a & APC-H7 & BD Pharmingen & $53-6.7$ & $1: 100$ & 560182 \\
CD4 & PE & BD Pharmingen & GK1.5 & $1: 400$ & 557308 \\
CD45 & FITC & BD Pharmingen & $30-\mathrm{F} 11$ & $1: 10$ & 553080 \\
CD44 & BUV395 & BD OptiBuild & IM7 & $1: 100$ & 740215 \\
KLRG1 & BB700 & BD OptiBuild & 2F1 & $1: 100$ & 742199 \\
PD-1 (CD279) & APC-R700 & BD Horizon & J43 & $1: 100$ & 565815 \\
CXCR3 (CD183) & BUV737 & BD OptiBuild & CXCR3-173 & $1: 100$ & 741895 \\
CX3CR1 & PE/Dazzle 594 & Biolegend & SA011F11 & $1: 100$ & 149014 \\
CD3e & V500 & BD Horizon & 500A2 & $1: 50$ & 560771 \\
TNF- $\alpha$ & PE-Cy7 & BD Pharmingen & MP6-XT22 & $1: 200$ & 557644 \\
IFN-y & Bv421 & BD Horizon & XMG1.2 & $1: 100$ & 563376 \\
IL-17A & BV786 & BD Horizon & TC11-18H10 & $1: 100$ & 564171 \\
IL-2 & APC & eBioscience & JES6-5H4 & $1: 100$ & $17-7021-82$ \\
\hline
\end{tabular}


(Tree Star). The graphical visualizations were done using GraphPad Prism v8.3.0. The type of statistical test performed together with the exact $P$ value is indicated in the individual figure legends. A $P$ value below 0.05 was considered significant.

Data availability. The data that support the findings of this study are available on request from the corresponding author.

\section{SUPPLEMENTAL MATERIAL}

Supplemental material is available online only.

FIG S1, TIF file, 1.4 MB.

FIG S2, TIF file, 0.4 MB.

FIG S3, TIF file, 0.9 MB.

FIG S4, TIF file, $0.2 \mathrm{MB}$.

FIG S5, TIF file, 0.3 MB.

\section{ACKNOWLEDGMENTS}

This work was supported by the Lundbeck Foundation (R249-2017-851) and the Independent Research Fund Denmark (DFF - 7025-00106) and the National Institutes of Health/National Institute of Allergy and Infectious Diseases (grant 1R01Al135721). Work in the laboratory of M.A.B. is supported by a Foundation Grant from the Canadian Institutes of Health Research (CIHR) Foundation (FDN-148362). The funders had no role in the study design, data collection, data analysis, interpretation, or writing of the report.

We acknowledge the NIH Tetramer Core Facility for provision of I-Ab:ESAT-6 $6_{4-17}$ and I-A $: \mathrm{MPT70}_{38-52}$ and corresponding negative-control tetramers I-Ab:hCLIP and the containment level 3 laboratory of the Research Institute of the McGill University Health Centre. Thanks to Andréanne Lupien and Sarah Danchuk for technical assistance and fruitful discussion on RNA extractions and qPCR assays. We thank Vivi Andersen, Ming Liu Olsen, and Camilla Haumann Rasmussen at SSI for their excellent technical assistance. We also gratefully acknowledge the mouse work done by the competent veterinarians and dedicated animal caretakers at Statens Serum Institut.

H.S.C., R.M., M.A.B., C.A., and P.A. conceived and designed the studies. H.S.C., J.-Y.D., and F.M. performed murine TB experiments. H.S.C. and R.M. analyzed and interpreted the data. G.J. took part in the supervision and provided intellectual content to the study. I.R. designed and produced the recombinant proteins including quality control and testing. H.S.C. and R.M. drafted the manuscript. H.S.C., M.A.B., P.A., and R.M. finalized the manuscript. All authors reviewed and commented on the final manuscript.

P.A., C.A., and R.M. are coinventors of patents covering a vaccine that includes both MPT70 and ESAT-6. P.A. and I.R. are also coinventors of patents covering the use of CAF01 as an adjuvant.

\section{REFERENCES}

1. World Health Organization. 2020. Global tuberculosis report 2020. World Health Organization, Geneva, Switzerland.

2. Gautam US, Mehra S, Kaushal D. 2015. In-vivo gene signatures of Mycobacterium tuberculosis in C3HeB/FeJ mice. PLoS One 10:e0135208. https://doi.org/10.1371/journal.pone.0135208.

3. Karakousis PC, Yoshimatsu T, Lamichhane G, Woolwine SC, Nuermberger EL, Grosset J, Bishai WR. 2004. Dormancy phenotype displayed by extracellular Mycobacterium tuberculosis within artificial granulomas in mice. J Exp Med 200:647-657. https://doi.org/10.1084/jem.20040646.

4. Sharma D, Bose A, Shakila H, Das TK, Tyagi JS, Ramanathan VD. 2006. Expression of mycobacterial cell division protein, FtsZ, and dormancy proteins, DevR and Acr, within lung granulomas throughout guinea pig infection. FEMS Immunol Med Microbiol 48:329-336. https://doi.org/10.1111/j .1574-695X.2006.00160.x.

5. Schnappinger D, Ehrt S, Voskuil MI, Liu Y, Mangan JA, Monahan IM, Dolganov G, Efron B, Butcher PD, Nathan C, Schoolnik GK. 2003. Transcriptional adaptation of Mycobacterium tuberculosis within macrophages: insights into the phagosomal environment. J Exp Med 198:693-704. https://doi.org/10.1084/jem.20030846.
6. Said-Salim B, Mostowy S, Kristof AS, Behr MA. 2006. Mutations in Mycobacterium tuberculosis Rv0444c, the gene encoding anti-SigK, explain high level expression of MPB70 and MPB83 in Mycobacterium bovis. Mol Microbiol 62:1251-1263. https://doi.org/10.1111/j.1365-2958.2006.05455.x.

7. Harboe M, Nagai S. 1984. MPB70, a unique antigen of Mycobacterium bovis BCG. Am Rev Respir Dis 129:444-452. https://doi.org/10.1164/arrd 1984.129.3.444.

8. Betts JC, Lukey PT, Robb LC, McAdam RA, Duncan K. 2002. Evaluation of a nutrient starvation model of Mycobacterium tuberculosis persistence by gene and protein expression profiling. Mol Microbiol 43:717-731. https:// doi.org/10.1046/j.1365-2958.2002.02779.x.

9. Fifis T, Corner LA, Rothel JS, Wood PR. 1994. Cellular and humoral immune responses of cattle to purified Mycobacterium bovis antigens. Scand J Immunol 39:267-274. https://doi.org/10.1111/j.1365-3083.1994.tb03370.x.

10. Haslov K, Andersen AB, Bentzon MW. 1987. Biological activity in sensitized guinea pigs of MPB 70, a protein specific for some strains of Mycobacterium bovis BCG. Scand J Immunol 26:445-454. https://doi.org/10.1111/j .1365-3083.1987.tb02277.x. 
11. Wiker HG. 2009. MPB70 and MPB83-major antigens of Mycobacterium bovis. Scand J Immunol 69:492-499. https://doi.org/10.1111/j.1365-3083 .2009.02256.x.

12. Ireton GC, Greenwald R, Liang H, Esfandiari J, Lyashchenko KP, Reed SG. 2010. Identification of Mycobacterium tuberculosis antigens of high serodiagnostic value. Clin Vaccine Immunol 17:1539-1547. https://doi.org/10 .1128/CVI.00198-10.

13. Bertholet S, Ireton GC, Kahn M, Guderian J, Mohamath R, Stride N, Laughlin EM, Baldwin SL, Vedvick TS, Coler RN, Reed SG. 2008. Identification of human $\mathrm{T}$ cell antigens for the development of vaccines against Mycobacterium tuberculosis. J Immunol 181:7948-7957. https://doi.org/ 10.4049/jimmunol.181.11.7948.

14. Windish HP, Duthie MS, Misquith A, Ireton G, Lucas E, Laurance JD, Bailor $\mathrm{RH}$, Coler RN, Reed SG. 2011. Protection of mice from Mycobacterium tuberculosis by ID87/GLA-SE, a novel tuberculosis subunit vaccine candidate. Vaccine 29:7842-7848. https://doi.org/10.1016/j.vaccine.2011.07 .094 .

15. Orr MT, Ireton GC, Beebe EA, Huang PW, Reese VA, Argilla D, Coler RN, Reed SG. 2014. Immune subdominant antigens as vaccine candidates against Mycobacterium tuberculosis. J Immunol 193:2911-2918. https:// doi.org/10.4049/jimmunol.1401103.

16. Ma J, Teng X, Wang X, Fan X, Wu Y, Tian M, Zhou Z, Li L. 2017. A multistage subunit vaccine effectively protects mice against primary progressive tuberculosis, latency and reactivation. EBioMedicine 22:143-154. https://doi.org/10.1016/j.ebiom.2017.07.005.

17. Caruso AM, Serbina N, Klein E, Triebold K, Bloom BR, Flynn JL. 1999. Mice deficient in CD4 T cells have only transiently diminished levels of IFNgamma, yet succumb to tuberculosis. J Immunol 162:5407-5416.

18. Lawn SD, Myer L, Edwards D, Bekker LG, Wood R. 2009. Short-term and long-term risk of tuberculosis associated with CD4 cell recovery during antiretroviral therapy in South Africa. AIDS 23:1717-1725. https://doi.org/ 10.1097/QAD.0b013e32832d3b6d.

19. Lin PL, Rutledge T, Green AM, Bigbee M, Fuhrman C, Klein E, Flynn JL. 2012. CD4 T cell depletion exacerbates acute Mycobacterium tuberculosis while reactivation of latent infection is dependent on severity of tissue depletion in cynomolgus macaques. AIDS Res Hum Retroviruses 28:1693-1702. https://doi.org/10.1089/AID.2012.0028.

20. Scanga CA, Mohan VP, Yu K, Joseph H, Tanaka K, Chan J, Flynn JL. 2000. Depletion of $\mathrm{CD} 4(+) \mathrm{T}$ cells causes reactivation of murine persistent tuberculosis despite continued expression of interferon gamma and nitric oxide synthase 2. J Exp Med 192:347-358. https://doi.org/10.1084/jem .192.3.347

21. Day $C L$, Abrahams DA, Lerumo $L$, Janse van Rensburg $E$, Stone $L, O$, Rie $T$, Pienaar B, de Kock M, Kaplan G, Mahomed H, Dheda K, Hanekom WA. 2011. Functional capacity of Mycobacterium tuberculosis-specific T cell responses in humans is associated with mycobacterial load. J Immunol 187:2222-2232. https://doi.org/10.4049/jimmunol.1101122.

22. Moguche AO, Musvosvi M, Penn-Nicholson A, Plumlee CR, Mearns $H$, Geldenhuys H, Smit E, Abrahams D, Rozot V, Dintwe O, Hoff ST, Kromann I, Ruhwald M, Bang P, Larson RP, Shafiani S, Ma S, Sherman DR, Sette A, Lindestam Arlehamn CS, McKinney DM, Maecker H, Hanekom WA, Hatherill M, Andersen P, Scriba TJ, Urdahl KB. 2017. Antigen availability shapes $T$ cell differentiation and function during tuberculosis. Cell Host Microbe 21:695-706.e5. https://doi.org/10.1016/j.chom.2017.05.012.

23. Han S, Asoyan A, Rabenstein H, Nakano N, Obst R. 2010. Role of antigen persistence and dose for CD4+ T-cell exhaustion and recovery. Proc Natl Acad Sci U S A 107:20453-20458. https://doi.org/10.1073/pnas.1008437107.

24. Sakai S, Kauffman KD, Schenkel JM, McBerry CC, Mayer-Barber KD, Masopust D, Barber DL. 2014. Cutting edge: control of Mycobacterium tuberculosis infection by a subset of lung parenchyma-homing CD4 T cells. J Immunol 192:2965-2969. https://doi.org/10.4049/jimmunol.1400019.

25. Sallin MA, Sakai S, Kauffman KD, Young HA, Zhu J, Barber DL. 2017. Th1 differentiation drives the accumulation of intravascular, non-protective CD4 T cells during tuberculosis. Cell Rep 18:3091-3104. https://doi.org/10 .1016/j.celrep.2017.03.007.

26. Chakravarty SD, Xu J, Lu B, Gerard C, Flynn J, Chan J. 2007. The chemokine receptor CXCR3 attenuates the control of chronic Mycobacterium tuberculosis infection in BALB/C mice. J Immunol 178:1723-1735. https://doi .org/10.4049/jimmunol.178.3.1723.

27. Hall JD, Kurtz SL, Rigel NW, Gunn BM, Taft-Benz S, Morrison JP, Fong AM, Patel DD, Braunstein M, Kawula TH. 2009. The impact of chemokine receptor CX3CR1 deficiency during respiratory infections with Mycobacterium tuberculosis or Francisella tularensis. Clin Exp Immunol 156:278-284. https://doi .org/10.1111/j.1365-2249.2009.03882.x.
28. Seiler P, Aichele P, Bandermann S, Hauser AE, Lu B, Gerard NP, Gerard C, Ehlers S, Mollenkopf HJ, Kaufmann SH. 2003. Early granuloma formation after aerosol Mycobacterium tuberculosis infection is regulated by neutrophils via CXCR3-signaling chemokines. Eur J Immunol 33:2676-2686. https://doi.org/10.1002/eji.200323956.

29. Clemmensen HS, Knudsen NPH, Billeskov R, Rosenkrands I, Jungersen G, Aagaard C, Andersen P, Mortensen R. 2020. Rescuing ESAT-6 specific CD4 $T$ cells from terminal differentiation is critical for long-term control of murine Mtb infection. Front Immunol 11:585359. https://doi.org/10.3389/ fimmu.2020.585359.

30. Hoang T, Aagaard C, Dietrich J, Cassidy JP, Dolganov G, Schoolnik GK, Lundberg CV, Agger EM, Andersen P. 2013. ESAT-6 (EsxA) and TB10.4 (EsxH) based vaccines for pre- and post-exposure tuberculosis vaccination. PLoS One 8:e80579. https://doi.org/10.1371/journal.pone.0080579.

31. Reiley WW, Calayag MD, Wittmer ST, Huntington JL, Pearl JE, Fountain JJ, Martino CA, Roberts AD, Cooper AM, Winslow GM, Woodland DL. 2008. ESAT-6-specific CD4 T cell responses to aerosol Mycobacterium tuberculosis infection are initiated in the mediastinal lymph nodes. Proc Natl Acad Sci U S A 105:10961-10966. https://doi.org/10.1073/pnas.0801496105.

32. Rogerson BJ, Jung YJ, LaCourse R, Ryan L, Enright N, North RJ. 2006. Expression levels of Mycobacterium tuberculosis antigen-encoding genes versus production levels of antigen-specific T cells during stationary level lung infection in mice. Immunology 118:195-201. https://doi.org/10 .1111/j.1365-2567.2006.02355.x.

33. Shi L, North R, Gennaro ML. 2004. Effect of growth state on transcription levels of genes encoding major secreted antigens of Mycobacterium tuberculosis in the mouse lung. Infect Immun 72:2420-2424. https://doi .org/10.1128/iai.72.4.2420-2424.2004.

34. Aagaard C, Knudsen NPH, Sohn I, Izzo AA, Kim H, Kristiansen EH, Lindenstrom T, Agger EM, Rasmussen M, Shin SJ, Rosenkrands I, Andersen P, Mortensen R. 2020. Immunization with Mycobacterium tuberculosis-specific antigens bypasses $\mathrm{T}$ cell differentiation from prior Bacillus Calmette-Guerin vaccination and improves protection in mice. J Immunol 205:2146-2155. https://doi.org/10.4049/jimmunol.2000563.

35. Agger EM, Rosenkrands I, Hansen J, Brahimi K, Vandahl BS, Aagaard C, Werninghaus K, Kirschning C, Lang R, Christensen D, Theisen M, Follmann F, Andersen P. 2008. Cationic liposomes formulated with synthetic mycobacterial cordfactor (CAF01): a versatile adjuvant for vaccines with different immunological requirements. PLoS One 3:e3116. https://doi.org/10 .1371/journal.pone.0003116.

36. Veyrier FJ, Nieves C, Lefrancois LH, Trigui H, Vincent AT, Behr MA. 2020. RskA is a dual function activator-inhibitor that controls SigK activity across distinct bacterial genera. Front Microbiol 11:558166. https://doi .org/10.3389/fmicb.2020.558166.

37. Hoft SG, Sallin MA, Kauffman KD, Sakai S, Ganusov VV, Barber DL. 2019. The rate of CD4 T cell entry into the lungs during Mycobacterium tuberculosis infection is determined by partial and opposing effects of multiple chemokine receptors. Infect Immun 87:e00841-18. https://doi.org/10 .1128/IAI.00841-18.

38. Lewinsohn DA, Lewinsohn DM, Scriba TJ. 2017. Polyfunctional CD4+ T cells as targets for tuberculosis vaccination. Front Immunol 8:1262. https://doi.org/10.3389/fimmu.2017.01262.

39. Petruccioli E, Petrone L, Vanini V, Sampaolesi A, Gualano G, Girardi E, Palmieri F, Goletti D. 2013. IFNgamma/TNFalpha specific-cells and effector memory phenotype associate with active tuberculosis. J Infect 66:475-486. https://doi.org/10.1016/j.jinf.2013.02.004.

40. Talaat AM, Lyons R, Howard ST, Johnston SA. 2004. The temporal expression profile of Mycobacterium tuberculosis infection in mice. Proc Natl Acad Sci U S A 101:4602-4607. https://doi.org/10.1073/pnas.0306023101.

41. Woodworth JS, Cohen SB, Moguche AO, Plumlee CR, Agger EM, Urdahl KB, Andersen P. 2017. Subunit vaccine H56/CAF01 induces a population of circulating CD4 T cells that traffic into the Mycobacterium tuberculosis-infected lung. Mucosal Immunol 10:555-564. https://doi.org/10.1038/ mi.2016.70.

42. Chackerian AA, Alt JM, Perera TV, Dascher CC, Behar SM. 2002. Dissemination of Mycobacterium tuberculosis is influenced by host factors and precedes the initiation of T-cell immunity. Infect Immun 70:4501-4509. https://doi.org/10.1128/iai.70.8.4501-4509.2002.

43. Shi L, Jung YJ, Tyagi S, Gennaro ML, North RJ. 2003. Expression of Th1-mediated immunity in mouse lungs induces a Mycobacterium tuberculosis transcription pattern characteristic of nonreplicating persistence. Proc Natl Acad Sci U S A 100:241-246. https://doi.org/10.1073/pnas.0136863100.

44. Dey B, Jain R, Gupta UD, Katoch VM, Ramanathan VD, Tyagi AK. 2011. A booster vaccine expressing a latency-associated antigen augments BCG 
induced immunity and confers enhanced protection against tuberculosis. PLoS One 6:e23360. https://doi.org/10.1371/journal.pone.0023360.

45. Khademi F, Derakhshan M, Yousefi-Avarvand A, Tafaghodi M, Soleimanpour S. 2018. Multi-stage subunit vaccines against Mycobacterium tuberculosis: an alternative to the BCG vaccine or a BCG-prime boost? Expert Rev Vaccines 17:31-44. https://doi.org/10.1080/14760584.2018.1406309.

46. Aagaard C, Hoang T, Dietrich J, Cardona PJ, Izzo A, Dolganov G, Schoolnik GK, Cassidy JP, Billeskov R, Andersen P. 2011. A multistage tuberculosis vaccine that confers efficient protection before and after exposure. Nat Med 17:189-194. https://doi.org/10.1038/nm.2285.

47. Comas I, Chakravartti J, Small PM, Galagan J, Niemann S, Kremer K, Ernst JD, Gagneux S. 2010. Human T cell epitopes of Mycobacterium tuberculosis are evolutionarily hyperconserved. Nat Genet 42:498-503. https://doi org/10.1038/ng.590.

48. Lindenstrom T, Moguche A, Damborg M, Agger EM, Urdahl K, Andersen P. 2018. T cells primed by live mycobacteria versus a tuberculosis subunit vaccine exhibit distinct functional properties. EBioMedicine 27:27-39. https://doi.org/10.1016/j.ebiom.2017.12.004.

49. Lindenstrom T, Woodworth J, Dietrich J, Aagaard C, Andersen P, Agger EM. 2012. Vaccine-induced th 17 cells are maintained long-term postvaccination as a distinct and phenotypically stable memory subset. Infect Immun 80:3533-3544. https://doi.org/10.1128/IAl.00550-12.

50. Kaech SM, Cui W. 2012. Transcriptional control of effector and memory CD8 + T cell differentiation. Nat Rev Immunol 12:749-761. https://doi .org/10.1038/nri3307.

51. Karmaus PWF, Chen $X$, Lim SA, Herrada AA, Nguyen TM, Xu B, Dhungana Y, Rankin S, Chen W, Rosencrance C, Yang K, Fan Y, Cheng Y, Easton J, Neale G, Vogel P, Chi H. 2019. Metabolic heterogeneity underlies reciprocal fates of TH17 cell stemness and plasticity. Nature 565:101-105. https://doi.org/10.1038/s41586-018-0806-7.

52. Sallusto F, Cassotta A, Hoces D, Foglierini M, Lanzavecchia A. 2018. Do memory CD4 T cells keep their cell-type programming: plasticity versus fate commitment? T-cell heterogeneity, plasticity, and selection in humans. Cold Spring Harb Perspect Biol 10:a029421. https://doi.org/10 $.1101 /$ cshperspect.a029421.

53. Moguche AO, Shafiani $S$, Clemons $C$, Larson RP, Dinh $C$, Higdon $L E$, Cambier CJ, Sissons JR, Gallegos AM, Fink PJ, Urdahl KB. 2015. ICOS and Bcl6-dependent pathways maintain a CD4 T cell population with memory-like properties during tuberculosis. J Exp Med 212:715-728. https:// doi.org/10.1084/jem.20141518.

54. Kramnik I, Beamer G. 2016. Mouse models of human TB pathology: roles in the analysis of necrosis and the development of host-directed therapies. Semin Immunopathol 38:221-237. https://doi.org/10.1007/s00281 -015-0538-9.

55. Kauffman KD, Sallin MA, Sakai S, Kamenyeva O, Kabat J, Weiner D, Sutphin M, Schimel D, Via L, Barry CE, III, Wilder-Kofie T, Moore I, Moore R, Barber DL. 2018. Defective positioning in granulomas but not lung-homing limits CD4 T-cell interactions with Mycobacterium tuberculosis-infected macrophages in rhesus macaques. Mucosal Immunol 11:462-473. https://doi.org/10.1038/ mi.2017.60

56. Kaushal D, Foreman TW, Gautam US, Alvarez X, Adekambi T, Rangel-Moreno J, Golden NA, Johnson AM, Phillips BL, Ahsan MH, Russell-Lodrigue KE, Doyle LA, Roy CJ, Didier PJ, Blanchard JL, Rengarajan J, Lackner AA, Khader SA, Mehra S. 2015. Mucosal vaccination with attenuated Mycobacterium tuberculosis induces strong central memory responses and protects against tuberculosis. Nat Commun 6:8533. https://doi.org/10.1038/ncomms9533.

57. Hu Z, Zhao HM, Li CL, Liu XH, Barkan D, Lowrie DB, Lu SH, Fan XY. 2018. The role of KLRG1 in human CD4+ T-cell immunity against tuberculosis. J Infect Dis 217:1491-1503. https://doi.org/10.1093/infdis/jiy046.

58. Adekambi T, Ibegbu CC, Cagle S, Kalokhe AS, Wang YF, Hu Y, Day CL, Ray SM, Rengarajan J. 2015. Biomarkers on patient T cells diagnose active tuberculosis and monitor treatment response. J Clin Invest 125:1827-1838. https://doi.org/10.1172/JCI77990.

59. Pollock KM, Whitworth HS, Montamat-Sicotte DJ, Grass L, Cooke GS, Kapembwa MS, Kon OM, Sampson RD, Taylor GP, Lalvani A. 2013. T-cell immunophenotyping distinguishes active from latent tuberculosis. J Infect Dis 208:952-968. https://doi.org/10.1093/infdis/jit265.

60. Nikitina IY, Kondratuk NA, Kosmiadi GA, Amansahedov RB, Vasilyeva IA, Ganusov VV, Lyadova IV. 2012. Mtb-specific CD27low CD4 T cells as markers of lung tissue destruction during pulmonary tuberculosis in humans. PLoS One 7:e43733. https://doi.org/10.1371/journal.pone.0043733.

61. Peters JS, Ismail N, Dippenaar A, Ma S, Sherman DR, Warren RM, Kana BD. 2020. Genetic diversity in Mycobacterium tuberculosis clinical isolates and resulting outcomes of tuberculosis infection and disease. Annu Rev Genet 54:511-537. https://doi.org/10.1146/annurev-genet-022820-085940.

62. Homolka S, Niemann S, Russell DG, Rohde KH. 2010. Functional genetic diversity among Mycobacterium tuberculosis complex clinical isolates: delineation of conserved core and lineage-specific transcriptomes during intracellular survival. PLoS Pathog 6:e1000988. https://doi.org/10.1371/ journal.ppat.1000988.

63. Stewart GR, Snewin VA, Walzl G, Hussell T, Tormay P, O'Gaora P, Goyal M, Betts J, Brown IN, Young DB. 2001. Overexpression of heat-shock proteins reduces survival of Mycobacterium tuberculosis in the chronic phase of infection. Nat Med 7:732-737. https://doi.org/10.1038/89113.

64. Bold TD, Banaei N, Wolf AJ, Ernst JD. 2011. Suboptimal activation of antigenspecific CD4+ effector cells enables persistence of M. tuberculosis in vivo. PLoS Pathog 7:e1002063. https://doi.org/10.1371/journal.ppat.1002063.

65. Tollefsen S, Pollock JM, Lea T, Harboe M, Wiker HG. 2003. T- and B-cell epitopes in the secreted Mycobacterium bovis antigen MPB70 in mice. Scand J Immunol 57:151-161. https://doi.org/10.1046/j.1365-3083.2003 .01211.x.

66. Wu S, Howard ST, Lakey DL, Kipnis A, Samten B, Safi H, Gruppo V, Wizel B, Shams H, Basaraba RJ, Orme IM, Barnes PF. 2004. The principal sigma factor sigA mediates enhanced growth of Mycobacterium tuberculosis in vivo. Mol Microbiol 51:1551-1562. https://doi.org/10.1111/j.1365-2958 .2003.03922.x. 